\title{
Pressure-Flow Studies in Hypertrophic Subaortic Stenosis *
}

\author{
Rafael R. Hernandez, Joseph C. Greenfield, JR., and \\ Benjamin W. McCall $\dagger$ \\ (From the Department of Medicine, Durham Veterans Administration Hospital and Duke \\ University Medical Center, Durham, N. C.)
}

In 1942 Robb and Robb (1) suggested that the outflow tract of the left ventricle might be obstructed by an asynchronous contraction of the deep bulbo spiral muscle bundle. Brock described a clinical entity resulting from muscular obstruction to the left ventricular outflow tract in 1957 (2). The pathological anatomy in eight such cases of muscular obstruction was presented by Teare in 1958 (3). Since these reports were published, there have been numerous studies dealing with the symptomatology, physical findings, and laboratory data in well-documented cases of hypertrophic subaortic stenosis (4-7).

Although the exact nature of left ventricular ejection in these patients is unknown, Brachfeld and Gorlin postulated that the initial phase of cardiac ejection is relatively unencumbered and that the obstruction to outflow produced by the hypertrophied septal muscle occurs late in systole (4). This concept was based primarily on pressure data, since the phasic aortic blood flow had not been measured. The pressure gradient technique provides a method whereby the instantaneous aortic blood flow can be estimated in the intact patient (8). The purpose of this report is to present the instantaneous blood flow and pressure obtained by this technique in the aorta of five patients with hypertrophic subaortic stenosis.

\section{Methods}

Five male patients were studied. The clinical (4), electrocardiographic (9), and roentgenographic (5) findings were consistent with the diagnosis of hypertrophic subaortic stenosis. The diagnosis was confirmed in all patients by routine cardiac catheterization studies, including the demonstration of a significant pressure

* Submitted for publication July 29, 1963; accepted November 7, 1963.

Supported by North Carolina Heart Association grant 82-1484.

† Supported by National Heart Institute fellowship HSP-14,261-Cl. drop within the left ventricular chamber, but not across the aortic valve, and the finding of a characteristic central aortic and peripheral pulsus bisferiens. In addition, either cinefluorograms or biplane angiocardiograms of the left ventricle, or both, were obtained on each patient. The possibility of a fixed subvalvular obstruction was excluded.

Five male subjects who had a history of mild hypertension but were normotensive without therapy at the time of study served as control subjects. These patients had no clinical evidence of left ventricular hypertrophy or of other cardiovascular disease.

The phasic blood flow and pressure were estimated in the thoracic aorta by the pressure gradient technique (8). This method is based on a simplification of the Navier-Stokes equations (8). An approximate relation between the axial pressure gradient $-\delta p / \delta z$, and the instantaneous blood flow, $q$, is given by

$$
-\frac{\delta p}{\delta z}=\frac{L \delta q}{\delta t}+R q
$$

where $p$ is lateral pressure, $z$ is the axial coordinate along the stream, and $t$ is time. The coefficients $L$ and $R$ represent the hydraulic inductance and resistance, respectively, and are defined by

and

$$
L=\frac{(1.1) \rho}{g \pi r^{2}},
$$

$$
R=\frac{(1.6) 8 \mu}{g \pi r^{4}},
$$

where $r$ is the vessel radius, $\rho$ is the blood density, $\mu$ is the blood viscosity, and $g$ is the gravitational constant. The factors 1.1 and 1.6 are experimentally obtained correction values which account for, among other things, the nonuniformity of the flow profile. A discussion of the validity of these equations appears elsewhere (8). Since the pressure gradient, $-\delta p / \delta z$, cannot be measured, the pressure difference, $\Delta \mathrm{P}$, is estimated over a finite distance, $\Delta Z$, and $\Delta P / \Delta Z$ is substituted in Equation 1 for $-\delta p / \delta z$. Equation 1 can be continuously solved for the flow, $q$, using an analog computer. The pressure gradient technique was evaluated in a flow generator and was found to measure phasic flow accurately through the range frequencies tested, i.e., 0.6 to 7 cycles per second (10). This technique should adequately measure the major features of both blood pressure and flow curves in the aorta. The instrumental techniques, manometric accuracy requirements, and calibration procedures used to obtain valid phasic flow and pressure data in man have been previously described $(11,12)$. 
A double lumen catheter having lateral pressure taps separated by four $\mathrm{cm}$ was used to obtain the pressure gradient. It was inserted percutaneously into the femoral artery and advanced under fluoroscopic control until the tip was about three $\mathrm{cm}$ above the aortic valve. Simultaneous pressure and flow data were recorded in the ascending aorta in all subjects. In patients with hypertrophic subaortic stenosis, the catheter was then pulled back into the descending thoracic aorta until the tip was just below the origin of the left subclavian artery; the recording was repeated. In one patient, E.B., (Table I) data were obtained only in the descending aorta. In this patient recordings were made in the control state and during an infusion of $2 \mu \mathrm{g}$ per minute of isoproterenol. In patients R.T. and M.M., data were obtained in the control state and after iv administration of $2 \mathrm{mg}$ of methoxamine hydrochloride.

Cardiac output was measured during the procedure by the indicator dilution technique using indocyanine green dye injected into the pulmonary artery and sampled from the brachial artery. A phonocardiogram and electrocardiogram were also recorded during the pressure-flow study. All recording of data was carried out on an $\emptyset p-$ tical recorder. ${ }^{1}$

As can be seen in Equations 2 and 3, a knowledge of the vessel radius is necessary for the application of Equation 1. The aortic radius in both the ascending and descending aorta was estimated angiographically before the pressure gradient study. A biplane angiographic unit ${ }^{2}$ was used to take three exposures a second after injection of $35 \mathrm{ml}$ of Renovist ${ }^{3}$ (sodium and methylglucamine diatrizoates) into the ascending aorta. The technique used to correct for the X-ray distortion and obtain the true vessel radius from these angiograms has been described in detail by Luchsinger, Sachs, and Patel (13). The mean value of the vessel radius thus obtained could then be substituted into Equation 1 and used at the time of the pressure gradient study to solve for the flow, $q$. In one patient, W.W., angiograms were not obtained, and the calibration of the phasic flow was obtained from the cardiac output as calculated by the indicator dilution technique. In this patient, mean flow in the descending aorta was assumed to be $70 \%$ of that in the ascending aorta.

In each patient, cardiac output, peak blood flow, peak blood velocity, time distribution of the phasic flow, and the peak power were calculated. Five successive flow contours were integrated planimetrically to obtain the stroke volume and cardiac output. Zero flow was assumed to be present at the end of diastole. The maximal value of the phasic flow curve represented the peak flow. The peak velocity was obtained by dividing the peak flow by the vessel cross-sectional area. The time distribution of the phasic flow in the ascending aorta was obtained by dividing the flow curves into equal parts as a function of time. The area of each half was meas-

1 Electronics for Medicine, Inc., White Plains, N. Y.

2 Elema-Schönander AB, Stockholm, Sweden.

${ }^{3}$ E. R. Squibb and Sons, New York, N. Y. ured planimetrically and expressed as a ratio of the total area. To obtain power, the product of the pressure times the flow every .01 second was calculated from a representative set of curves from the ascending aorta in the four patients and the five control subjects. The maximal value was recorded as the peak power.

\section{Results}

In the upper panel of Figure 1 the pressure gradient, blood flow, and the pressure pulse in the ascending aorta of a normal subject, J.W., are illustrated. Note that this normal flow pulse accelerates to a peak flow of $400 \mathrm{~cm}^{3}$ per second in the first third of systole and gradually decelerates so that $58 \%$ of the total stroke volume is ejected during the first half of systole. The flow curve ends in a negative dip associated with closure of the aortic valve. The lower panel of Figure 1 illustrates the same data obtained from patient W.W. with hypertrophic subaortic steno-
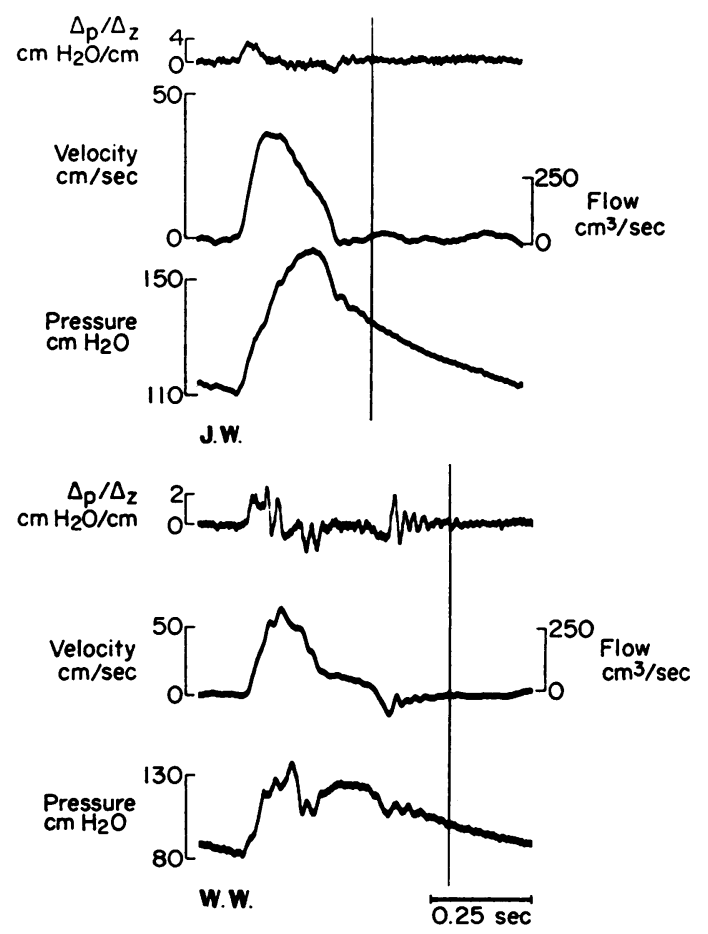

Fig. 1. The UPPER three tracings, From the toP DOWN, ARE THE PRESSURE GRADIENT, THE COMPUTED PHASIC BLOOD FLOW AND VELOCITY, AND THE PRESSURE RECORDED FROM THE ASCENDING AORTA OF A NORMAL SUBJeCt, J.W. THE LOWER PANel SHOWS THE SAME DATA FROM PATIENT W.W. WITH HYPERTROPHIC SUBAORTIC STENOSIS. Note that the calibration scales are different for the two sets of data. 


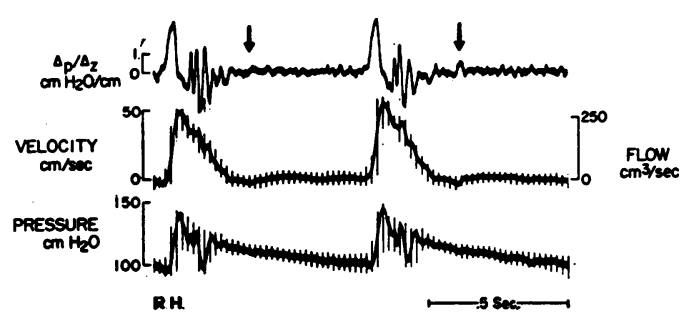

Fig. 2. The THREE TRACINGS, FROM THE TOP DOWN, ARE THE PRESSURE GRADIENT, THE COMPUTED PHASIC BLOOD FLOW AND VELOCITY, AND THE PRESSURE RECORDED FROM THE DESCENDING AORTA OF PATIENT R.H. WITH HYPERTROPHIC SLBAORTIC STENosis. The arrow above the pressure gradient denotes the end of systole.

sis. The flow pulse accelerates to a peak flow of $324 \mathrm{~cm}^{3}$ per second during the first third of systole. This is soon followed by rapid deceleration of flow during the last half of systole so that $79 \%$ of the stroke volume occurs during the first half. The flow curve also ends in a negative dip as noted in the normal curve. The two curves differ most markedly in the relative degree of flow during the first half of systole. In Figure 2 blood flow in the descending aorta of patient R.H. is illustrated. In this patient, the deceleration of flow during midsystole is so marked that orthograde flow during the latter third of systole is the same as that during diastole. These latter two flow contours are typical of those obtained from our five patients with hypertrophic subaortic stenosis.

In Figure 3 (upper panel), the blood flow, pressure gradient, and pressure pulse obtained in the descending aorta of patient E.B. during the control state are illustrated. In the lower panel of Figure 3, data from the same subject are illustrated during infusion of isoproterenol. Note the marked change in the flow contour during isoproterenol infusion so that the major portion of the flow now occurs in the first half of systole.

In two patients the phasic flow was obtained after administration of $2 \mathrm{mg}$ of methoxamine hydrochloride. In these patients the mean blood pressure rose $30 \mathrm{~cm}$ of water. The contour of the flow and pressure curves was unchanged from that of the control curves.

In the upper part of Table I, various measurements obtained from the flow and pressure curves and the hemodynamic and angiographic studies on the patients with hypertrophic subaortic sten- osis are tabulated. In column 1 the peak intraventricular pressure gradients are listed, and in column 3 the mean cross-sectional aortic areas obtained angiographically are given. The values of peak blood velocity noted in column 4 ranged between 33.0 and $56.7 \mathrm{~cm}$ per second in the ascending aorta and from 44.4 to $78.3 \mathrm{~cm}$ per second in the descending aorta. The peak flow (column 5 ) in the ascending aorta ranged from 324 to $397 \mathrm{~cm}^{3}$ per second and from 229 to $290 \mathrm{~cm}^{3}$ per second in the descending aorta. The percentage of total flow occurring in the first half of systole is given in column 6 . The values ranged from 77 to $85 \%$. In columns 7 and 8 the mean flow obtained by the pressure gradient technique and the indictator dilution technique, respectively, are listed. Column 9 gives the values for peak power, which ranged from 40,500 to $57,565 \mathrm{~g}-\mathrm{cm}$ per second.

In Table I the data from the five control subjects are expressed as means and standard deviations in their respective columns. The only statistically significant difference between the two groups consists of the percentage of flow during the first half of systole. The control group has a
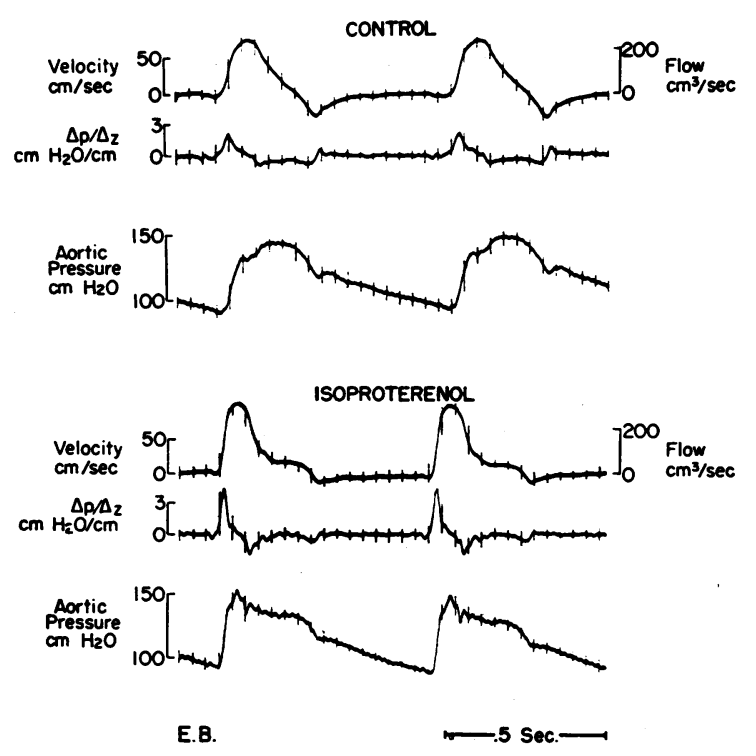

Fig. 3. ThE UPPER THREE TRACINGS, FROM THE TOP DOWN, ARE THE COMPUTED PHASIC BLOOD FLOW AND VELOCITY, THE PRESSURE GRADIENT, AND THE PRESSURE RECORDED FROM THE DESCENDING AORTA OF PATIENT E.B. WITH HYPERTROPHIC SUBAORTIC STENOSIS. THE LOWER panel contains the same data in patient E.B. DURING THE INFUSION OF ISOPROTERENOL. 
TABLE I

Hemodynamic data

\begin{tabular}{|c|c|c|c|c|c|c|c|c|c|c|}
\hline Patient & $\begin{array}{l}\text { Site of flow } \\
\text { measurement }\end{array}$ & $\begin{array}{c}(1) \\
\text { Intra- } \\
\text { ventricular } \\
\text { gradient }\end{array}$ & $\begin{array}{l}(2) \\
\text { Heart } \\
\text { rate }\end{array}$ & $\begin{array}{l}(3) \\
\text { Aortic } \\
\text { area }\end{array}$ & $\begin{array}{c}(4) \\
\text { Peak } \\
\text { velocity }\end{array}$ & $\begin{array}{c}\text { (5) } \\
\text { Peak } \\
\text { flow }\end{array}$ & $\begin{array}{l}\text { (6) } \\
\text { Flow in } \\
\text { first half } \\
\text { of systole }\end{array}$ & Mean flow & $\begin{array}{l}\text { (8) } \\
\text { Cardiac } \\
\text { output }\end{array}$ & $\begin{array}{c}\text { (9) } \\
\text { Peak } \\
\text { power }\end{array}$ \\
\hline & & $\mathrm{cm} \mathrm{H}_{2} \mathrm{O}$ & beats/min & $\mathrm{cm}^{2}$ & $\mathrm{~cm} / \mathrm{sec}$ & $\mathrm{cm}^{3} / \mathrm{sec}$ & $\%$ & $\mathrm{~cm}^{3} / \min$ & $\mathrm{cm}^{3 / m i n}$ & $\mathrm{~g}-\mathrm{cm} / \mathrm{sec}$ \\
\hline \multirow[t]{2}{*}{ R.T. } & Asc.* & 96 & 70 & 6.61 & 56.7 & 374 & 79 & 4,032 & 3,620 & 54,230 \\
\hline & Desc. & & 74 & 3.61 & 78.3 & 283 & & 2,160 & & \\
\hline \multirow[t]{2}{*}{ M.M. } & Asc. & 101 & 71 & 10.70 & 33.0 & 353 & 77 & 3,800 & 3,529 & 49,420 \\
\hline & Desc. & & 71 & 3.80 & 76.2 & 290 & & 2,596 & & \\
\hline \multirow[t]{2}{*}{ R.H. } & Asc. & 61 & 85 & 8.60 & 46.2 & 397 & 85 & 5,800 & 5,275 & 57,556 \\
\hline & Desc. & & 85 & 6.15 & 44.4 & 273 & & 3,690 & & \\
\hline \multirow[t]{2}{*}{ W.W. } & Asc. & 104 & 68 & & & 324 & 79 & & 3,380 & 40,500 \\
\hline & Desc. & & 68 & & & 235 & & & & \\
\hline E.B. & Desc. & 83 & 80 & 3.10 & 74.4 & 229 & & 4,300 & 6,000 & \\
\hline Control & Asc. & & $\begin{array}{c}83 \\
S D \pm 10\end{array}$ & $\begin{array}{c}9.69 \\
\mathrm{SD} \pm 2.17\end{array}$ & $\begin{array}{c}37.9 \\
\mathrm{SD} \pm 8.79\end{array}$ & $\begin{array}{c}354 \\
\mathrm{SD} \pm 34.6\end{array}$ & $\begin{array}{c}57 \\
S D \pm 2.6\end{array}$ & $\begin{array}{c}5,460 \dagger \\
S D \pm 1,040\end{array}$ & $\begin{array}{c}4,989 \dagger \\
\mathrm{SD} \pm 902\end{array}$ & $\begin{array}{c}59,396 \\
\mathrm{SD} \pm 9,037\end{array}$ \\
\hline
\end{tabular}

* Asc. = ascending aorta, desc. = descending thoracic aorta.

+ Calculated on four subjects.

value of $57 \%(\mathrm{SD} \pm 2.6)$, and the patient group, $80 \%(\mathrm{SD} \pm 3.5)$, representing a significant difference, $\mathrm{p}<.001$.

\section{Discussion}

The marked decrease in orthograde flow during the latter half of systole has been found only in patients with hypertrophic subaortic stenosis. This finding has not been observed in normal subjects, in patients with nonvalvular myocardial diseases of various etiologies, or in patients with mitral valvular disease, studied by the pressure gradient technique in other laboratories $(12,14)$. Also, phasic blood flow measured with an electromagnetic flowmeter in the ascending aorta of patients during surgery has not revealed an abrupt decrease in cardiac ejection during the latter part of systole (15). This decreased ejection of blood in the last half of systole in patients with hypertrophic subaortic stenosis is documented by the finding that in our four patients $80 \%(\mathrm{SD} \pm 3.5)$ of the stroke output occurs during the first half of systole. In contrast, our normal subjects ejected only $57 \% \quad(\mathrm{SD} \pm 2.6)$ of the total stroke volume during the same period. In a group of ten patients with various cardiac abnormalities studied by the same technique (12, $14), 61 \%(\mathrm{SD} \pm 4.2)$ of the stroke volume occurred during the first half of systole. The difference between this group and our patients with hypertrophic subaortic stenosis is highly significant $(\mathrm{p}<.001)$.
The mechanism for the marked decrease in ventricular ejection during the last half of systole has not been determined. The intraventricular pressure drop characteristic of these patients has led to the postulate that obstruction to flow takes place late in systole because of a constricting ring of hypertrophied muscle in the outflow tract of the left ventricle below the aortic valve (4). This pressure drop, however, is not in itself proof of a discrete obstruction in the infundibulum. An abnormally powerful and rapid contraction of the ventricle may possibly produce almost total ejection early in systole so that late in systole there remains a virtually empty ventricle contracting on the catheter tip trapped in small, isolated pockets of blood among the trabeculae. If the mitral valvular insufficiency present in these patients occurs predominantly late in systole, it could contribute to the empty ventricle and the decrease in orthograde flow late in systole. Careful ventricular volume studies will be necessary to settle this question.

In Figure 3, the effect of isoproterenol on the aortic flow curve is illustrated. The use of this drug to change the dynamics of ventricular contraction and thus increase the intraventricular gradient in subjects with hypertrophic subaortic stenosis has been described previously $(16,17)$. To date we have studied the phasic flow in only a few normal subjects after administration of isoproterenol but have not found a change in the flow contour similar to that in Figure 3. This 


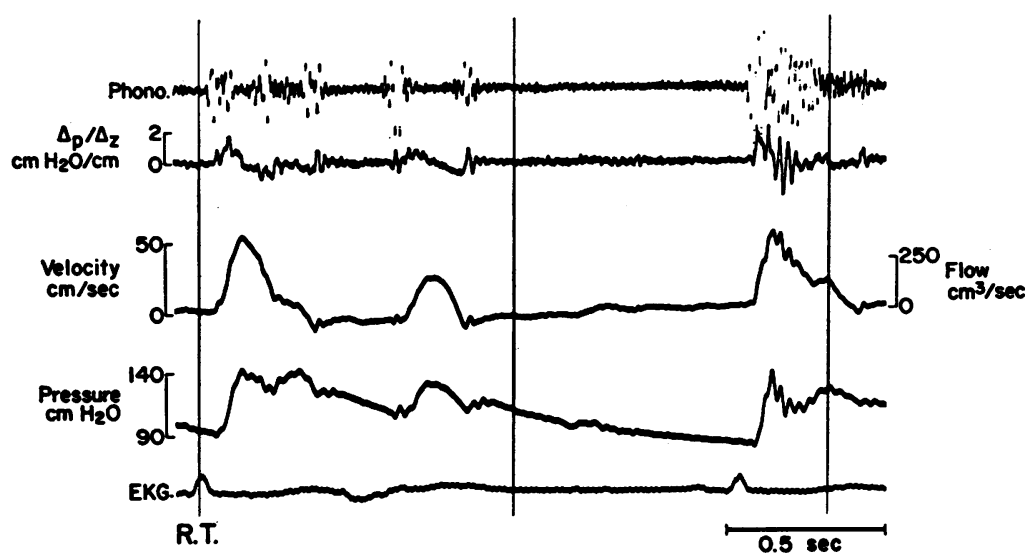

Fig. 4. The five tracings, from the top down, ARE A Left Sternal EDGE PHONOCARDIOGRAM, THE PRESSURE GRADIENT, THE PHASIC BLOOD FLOW AND VELOCITY, THE CENTRAL AORTIC PRESSURE, AND LEAD II OF THE ELECTROCARDIOGRAM. The pressure and flow data were recorded from the ascending aorta.

finding agrees with the experience of other investigators (12).

Braunwald and Ebert (17) have found that administration of methoxamine hydrochloride reduced the intraventricular pressure drop in patients with hypertrophic subaortic stenosis. This drug failed to alter the flow contour in the two patients that we studied. Our data would suggest that the abnormal mechanism of ejection is not appreciably altered by moderately increasing the hydraulic load presented to the left ventricle by administration of methoxamine hydrochloride. However, since a decrease in the intraventricular pressure drop was not documented by simultaneous measurement of the left ventricular pressure, we cannot state whether the effect of the drug as noted by Braunwald and Ebert (17) was achieved.

In Figures 1 and 4, the central pulsus bisferiens is illustrated. The finding of a bisferious pulse in a peripheral artery is not an uncommon one, yet its presence in the central aorta is quite unusual (18) and was first described by Brachfeld and Gorlin as typical of patients with hypertrophic subaortic stenosis (4). The mechanism of the second peak on the pressure pulse has been ascribed to a second rapid ejection of blood (19). In our subjects, however, the deceleration of flow was not followed by a secondary flow peak. Thus, the postulate that there is a secondary rapid ejection of blood by the heart does not seem tenable.
At least two explanations for this finding are possible: 1 ) the presence of reflected pressure waves which summate with the orthograde pressure wave, or 2) a negative dip in the pressure because of the rapid deceleration of blood. The first of these cannot be evaluated unless pressure is known at every point in the arterial system at the same time, but undoubtedly reflected waves are present. In each case the negative dip in the pressure pulse occurs during the rapid deceleration of blood. According to Newton's second law, a negative pressure will develop coincident with rapid deceleration of flow. This negative pressure superimposed on the pressure pulse could account for the bisferious contour.

Normal subjects and patients with fixed obstruction of the left ventricular outflow tract (aortic valvular stenosis or membranous subaortic stenosis) characteristically have a higher pulse pressure in the postextrasystolic beat than in a normal beat (6). Assuming a constant vascular tone, the higher pulse pressure in the postextrasystolic beat must be the result of a larger stroke volume. This increased stroke volume is presumably caused by a prolonged ventricular filling time resulting in a larger end diastolic volume. Brockenbrough, Braunwald, and Morrow (6) described a reversal of this phenomenon as measured in the brachial arteries of patients with hypertrophic subaortic stenosis, i.e., the postextrasystolic beat has a lower pulse pressure than a 
normal beat. If again one assumes a constant vascular tone, the lower pulse pressure must result from a lower stroke volume.

The phonocardiogram, pressure gradient, blood flow, pressure pulse, and electrocardiogram of patient R.T. obtained during a single premature ventricular contraction are illustrated in Figure 4. In this patient, the pulse pressure, stroke volume, and flow contour of the postextrasystolic beat are not too different from the control beat. Although the pulse pressure decrease described by Brockenbrough and associates (6) is not present in the central aorta of this patient, the response is definitely abnormal in that a higher pulse pressure and stroke volume are not observed after a prolonged compensatory pause. Three explanations for this phenomenon are possible: 1) the volume ejected is limited by a greater degree of obstruction, as evidenced by the increased intraventricular pressure gradient in the postextrasystolic beat $(6), 2)$ there is more mitral insufficiency during this beat so that there is no increase in the forward flow, or 3) the prolonged filling period during the compensatory pause does not actually result in a larger end-diastolic volume. This finding is limited, however, to a single observation.

Another interesting point is that the murmur during the postextrasystolic beat is louder than the control in spite of a lack of increase in forward flow. This suggests the presence of more turbulence possibly caused by a greater degree of obstruction to forward flow or a greater amount of regurgitation through the mitral valve, or both.

In Table I, column 7 , the flow per minute is given. The figure in the ascending aorta represents the cardiac output minus coronary flow. In column 8 , the values for cardiac output obtained by the indicator dilution technique are listed. Although the agreement is fairly good, note that the pressure gradient technique tends to overestimate the cardiac output in each case. The reason for this discrepancy is at least in part caused by the difficulty in accurately estimating the vessel radius. Since the blood pressure at the time of the aortogram is unknown, and since the cross-sectional area of the ascending aorta may change in the order of $10 \%$ during cardiac systole, the discrepancy is easily understood (20). The flow values per minute obtained in the de- scending aorta point out a further difficulty in the study of phasic blood flow. In the ascending aorta the assumption of zero flow at the end of diastole is probably valid. In the descending aorta, however, this is probably not the case. Since our technique cannot define zero flow, we must use the flow value at the end of diastole as zero. That this assumption is subject to error is illustrated by patient R.T. Note that the flow in the descending aorta was only about one-half of that in the ascending aorta. Since only approximately one-third of the cardiac output goes to the head and upper extremities, the value obtained is probably low because of orthograde flow during diastole.

\section{Summary}

Phasic aortic blood flow measured by the pressure gradient technique was recorded in five patients with hypertrophic subaortic stenosis and in five control subjects. The flow curve in the patient group is characterized by an abnormally rapid decrease in flow during midsystole, resulting in approximately $80 \%$ of the stroke volume occurring in the first half of systole. In the control subjects, only $57 \%$ of the stroke volume occurred during the first half of systole. The difference between these groups is highly significant, $p<$ .001 . The possible effect of this deceleration of flow in the production of a central bisferious pulse is discussed. An infusion of isoproterenol appears to accentuate this abnormality. On a single observation the phasic flow in the postextrasystolic beat shows no significant difference in contour or magnitude from the control beat.

\section{Acknowledgments}

The technical support of Miss Corinna Thomas and Mrs. Nancy Cash is gratefully acknowledged.

\section{References}

1. Robb, J. S., and R. C. Robb. The normal heart. Amer. Heart J. 1942, 23, 455.

2. Brock, R. Functional obstruction of the left ventricle. Guy's Hosp. Rep. 1957, 106, 221.

3. Teare, D. Asymmetrical hypertrophy of the heart in young adults. Brit. Heart J. 1958, 20, 1.

4. Brachfeld, N., and R. Gorlin. Subaortic stenosis: a revised concept of the disease. Medicine (Baltimore) 1959, 38, 415.

5. Braunwald, E., A. G. Morrow, W. P. Cornell, M. M. Aygen, and T. F. Hilbish. Idiopathic hypertrophic subaortic stenosis. Amer. J. Med. 1960, 29, 924. 
6. Brockenbrough, E. C., E. Braunwald, and A. G. Morrow. A hemodynamic technic for the detection of hypertrophic subaortic stenosis. Circulation 1961, 23, 189.

7. McIntosh, H. D., W. C. Sealy, R. E. Whalen, A. I. Cohen, and R. G. Sumner. Obstruction to outflow tract of left ventricle. Arch. intern. Med. 1962, $110,312$.

8. Fry, D. L. The measurement of pulsatile blood flow by the computed pressure gradient technique. Institute of Radio Engineers, Trans. med. Electronics 1959, ME-6, 259.

9. Estes, E. H., Jr., R. E. Whalen, S. R. Roberts, Jr., and H. D. McIntosh. The electrocardiographic and vectorcardiographic findings in idiopathic hypertrophic subaortic stenosis. Amer. Heart J. 1963, 65, 155.

10. Greenfield, J. C., Jr., D. J. Patel, A. J. Mallos, and D. L. Fry. Evaluation of Kolin type electromagnetic flowmeter and the pressure gradient technique. J. appl. Physiol. 1962, 17, 372.

11. Greenfield, J. C., Jr., and D. L. Fry. Measurement errors in estimating aortic blood velocity by pressure gradient. J. appl. Physiol. 1962, 17, 1013.

12. Barnett, G. O., J. C. Greenfield, Jr., and S. M. Fox III. The technique of estimating the instantaneous aortic blood velocity in man from the pressure gradient. Amer. Heart J. 1961, 62, 359.
13. Luchsinger, P. C., M. Sachs, and D. J. Patel. Pressure-radius relationship in large blood vessels of man. Circulat. Res. 1962, 11, 885.

14. Porje, I. G., and B. Rudewald. Hemodynamic studies with differential pressure technique. Acta physiol. scand. 1961, 51, 116.

15. Patel, D. J., J. C. Greenfield, Jr., W. G. Austen, and G. T. Tindall. Impedance of certain large blood vessels in man. Proc. Conf. Computers Med. and Biol., New York Acad. Sci., in press.

16. Whalen, R. E., A. I. Cohen, R. G. Sumner, and H. D. McIntosh. A demonstration of the dynamic nature of hypertrophic subvalvular aortic stenosis (abstract). J. clin. Invest. 1962, 41, 1411.

17. Braunwald, E., and P. A. Ebert. Hemodynamic alterations in idiopathic hypertrophic subaortic stenosis induced by sympathomimetic drugs. Amer. J. Cardiol. 1962, 10, 489.

18. Hansen, P. F., H. G. Davidsen, and J. Fabrius. Subvalvular aortic stenosis of muscular type. Acta med. scand. 1962, 171, 743.

19. Boiteau, G. M., and B. J. Allenstein. Hypertrophic sub-aortic stenosis. Amer. J. Cardiol. 1961, 8, 614.

20. Greenfield, J. C., Jr., and D. J. Patel. Relation between pressure and diameter in the ascending aorta of man. Circulat. Res. 1962, 10, 778. 